\title{
Why Oceanography?
}

Kenneth Brink

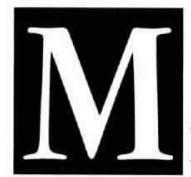

any of us in the academic world partake of the guilty pleasure of immersing ourselves in the joy of our own research without contemplating the broader context. And why not? We would not be part of this enterprise unless we took pleasure in finding new modes of hydrodynamic instability or in discovering new facets to the life cycle of an important copepod. Still, it is useful and informative to consider why hard-nosed people in Washington would spend money on the ocean sciences. Many oceanographers would respond that funds are committed because the ocean is important for climate, national defense, fisheries science, or a range of other reasons. Indeed, at the recent 1999 Reno meeting of The Oceanography Society, Joanne Bourgeois's talk on tsunamis brought home in graphic and invigorating detail why coastal hazards are so relevant to human well-being. There is a range of important, traditional reasons for supporting ocean science along these lines, but we might also consider two other aspects of the ocean sciences that we perhaps consider less often.

One aspect lending importance to the ocean sciences is how we contribute to the sciences as a whole. It is not direct practical applications that are important here, but rather the unanticipated ways in which our own science leads to advances in other fields. An example from the Reno meeting was the wonderful talk by Heidi Cullen, who showed how studying ocean sediment cores could lead to a clearer understanding of the role of climate in the collapse of the ancient Akkadian empire. Another example, embodied in the work of Holger Jannasch at hydrothermal vents, has implications that we will probably not even comprehend in our own lifetimes. We stand in awe of the idea of a new kingdom of life and the concept that life does not require sunlight or conditions that we would normally consider hospitable. We are now dealing with issues of life on other planets or deep within our earth's crust from an entirely different perspective.

Second, the National Research Council broadened our perspective by releasing the report "Monsoons to Microbes: Understanding the Ocean's Role in Human Health." To the many of us who do not often think of relations between health and the oceans, this study presents new and useful topics. We are used to thinking about harmful algal blooms and how they affect people, but do we often think of cholera being spread and nurtured in the ocean? We are familiar with losses associated with coastal hazards, but does the public often think of the ocean as a place to prospect for important new medicines? Here is a whole new set of ways to think of how ocean science ultimately serves the public.

Many of us in the ocean science enterprise do not do work that has immediate payoff outside our area of basic research. Nonetheless, we all believe, and for good reason, that our work contributes to a greater good. It is useful for each of us to be able to see what that path to greater good might be, and to be able to explain it clearly the next time someone in the neighboring airplane seat asks why she should care about the oceans.

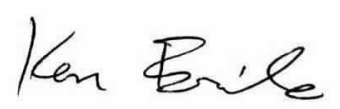

This special issue was made possible by the U.S. Office of Naval Research.

This work relates to Department of Navy grant N00014-99-1-0434 issued by the Office of Naval Research.

The United States Government has a royalty-free license throughout the world in all copyrightable material contained herein.

Abstracts were previously published, unedited, as Oceanography, Vol. 12, No. 2 Supplement. 